\title{
Efeitos colaterais ao meio ambiente durante a pandemia da COVID-19 no Brasil
}

\section{Rafael Mozart da Silva}

Universidade Federal do Rio Grande do Sul. Campus Litoral Norte. Rodovia RS-030, km 92, no 11700. Distrito de Emboaba. Tramandaí-RS, Brasil (CEP 95590-000). E-mail: rafael.mozart@ufrgs.br.

Resumo. Dentre os impactos do cenário pandêmico no Brasil, está o aumento da geração do lixo doméstico e hospitalar. 0 descarte e a destinação de forma adequada dos resíduos, tornamse elementos essenciais para a não propagação do vírus e por consequência auxiliam na conservação do meio ambiente. 0 Brasil possui ainda muitos locais de disposição final inadequada, como lixões e aterros, que acabam gerando graves implicações para a saúde pública e para o meio ambiente, sendo necessárias ações efetivas e urgentes para a superação desse déficit e cumprimento das disposições e diretrizes da Política Nacional de Resíduos Sólidos (PNRS). 0 atual cenário pandêmico gera consequências graves ao país no âmbito da saúde, porém é necessário perceber os efeitos colaterais ao meio ambiente, pois o tratamento dos resíduos é transversal a diversas questões ambientais, sociais e econômicas e sua contribuição para mitigação do Sars-CoV-2, causador da COVID-19, é considerável e não pode ser desprezada. 0 cuidado com o meio ambiente no Brasil, deve ser uma pauta permanente nas diferentes esferas governamentais e também do coletivo populacional, pois o esforço na busca de solução para conter o Sars-CoV-2, deve servir de aprendizado e inspiração para manutenção adequada do tratamento dos resíduos no país.

Palavras-chave: Meio ambiente; Recursos naturais; COVID-19; Pandemia; Sars-CoV-2.

Abstract. Side effects on the environment during the COVID-19 pandemic in Brazil. Among the impacts of the pandemic scenario in Brazil is the increase in the generation of household and hospital waste. The proper disposal and destination of waste become essential elements for the non-spread of the virus and, consequently, help in the conservation of the environment. Brazil still has many places with inadequate final disposal, such as dumps and landfills, which end up generating serious implications for public health and the environment, requiring effective and urgent actions to overcome this deficit and comply with the provisions and guidelines of the Brazilian National Solid Waste Policy. The current pandemic scenario has serious health consequences for the country, but it is necessary to realize the
Recebido

$01 / 07 / 2021$

Aceito

09/07/2021

Disponível on line

$11 / 07 / 2021$

Publicado

$31 / 08 / 2021$

Acesso aberto

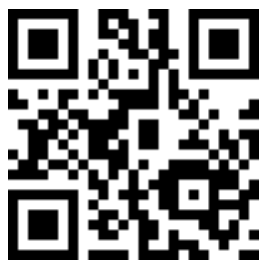

ORCIL

D 0000-0003-0314-757X Rafael Mozart da Silva 
side effects to the environment, as the treatment of waste cuts across several environmental, social and economic issues and its contribution to mitigating the COVID-19 it is considerable and cannot be overlooked. Care for the environment in Brazil must be a permanent agenda in different government spheres and also in the population collective, as the effort to find a solution to contain the Sars-CoV-2 must serve as a learning and inspiration for the proper maintenance of the waste treatment in the country.

Keywords: Environment; Natural resources; COVID-19; Pandemic; Sars-CoV-2.

O Brasil, assim como muitos outros países, está passando por uma crise sem precedentes em seu sistema de saúde, com consequências socioeconômicas e de saúde em escalas catastróficas (The Lancet, 2020; Taylor, 2021). 0 Brasil atingiu em junho de $2021 \mathrm{a}$ marca de 18.054.653 casos e 504.717 mortes pela COVID-19 (JHU, 2021) e os números são crescentes a cada dia, observando-se uma curva ascendente de contágio. A pandemia ocasionada pelo Sars-CoV-2, causador da COVID-19, tem gerado impactos na área da saúde, mas também é preciso atenção e um "olhar" permanente para o meio ambiente.

Apesar de mais de uma década de vigência da Política Nacional de Resíduos Sólidos, instituída pela Lei no 12.305/2010 (Brasil, 2010), o país enfrenta desafios relacionados ao descarte e também quanto à capacidade de reciclagem dos materiais (ANCAT, 2020). De acordo com a Associação Brasileira de Empresas de Limpeza Pública e Resíduos Especiais (ABRELPE, 2020) a geração de resíduos sólidos urbanos (RSU) atingiu a marca de 79,6 milhões de toneladas em 2020. Conforme a pesquisa realizada pela ABRELPE, os resíduos orgânicos representam 45\%, os resíduos recicláveis representam aproximadamente $35 \%$, sendo compostos principalmente por plásticos $(16,8 \%)$, o qual o país recicla apenas $1,28 \%$ do total. Os rejeitos, por sua vez, correspondem a $14 \%$ e são, sobretudo, os materiais sanitários, já os resíduos têxteis, couros e borrachas representam $5 \%$ e outros resíduos totalizam 1\%. Além disso, a prática de uma adequada política de gestão de RSU possibilita a mitigação da emissão de gases do efeito estufa, porém verificase um aumento de $23 \%$ nas emissões no país, sendo que dois terços são provenientes de atividades de disposição final, como os aterros sanitários, aterros controlados e lixões (Bocchini, 2020).

Dentre os impactos do cenário pandêmico no Brasil, está o aumento da geração do lixo doméstico, domiciliar e hospitalar (Guimarães, 2020). Em razão das medidas restritivas impostas pelos governos locais, há um aumento do lixo doméstico e domiciliar, pois as pessoas têm ficado em suas residências por um maior período de tempo e esse lixo é composto por resíduos orgânicos, materiais descartáveis e outros, os quais requerem nesse momento de pandemia tratativas adequadas em função do potencial de contaminação pelo Sars-CoV-2. O descarte e a destinação de forma adequada dos resíduos sólidos tornam-se elementos essenciais para a não propagação do vírus e por consequência auxiliam na conservação do meio ambiente. Deve-se estar atento ao "lixo hospital", pois o sistema de saúde brasileiro próximo de um colapso acaba aumentando o fluxo de pacientes e por sua vez o volume de lixo, composto por materiais contaminados e equipamentos de proteção (EPI's). Em razão da pandemia, houve um aumento substancial da utilização de EPI's, os quais têm em sua composição o plástico, matéria-prima essa que o país recicla muito pouco, gerando um ciclo vicioso e prejudicial ao meio ambiente.

O Brasil possui ainda muitos locais de disposição final inadequada, como lixões e aterros, que acabam gerando graves implicações para a saúde pública e para o meio ambiente, sendo necessárias ações efetivas e urgentes para a superação desse déficit e 
cumprimento das disposições e diretrizes da PNRS, as quais em um cenário pandêmico podem auxiliar a mitigar a propagação da COVID-19, principalmente nas populações de baixa renda. Segundo o Instituto Brasileiro de Geografia e Estatística (IBGE, 2020) as populações de baixa renda em 2019 , representavam 6,5\% da população brasileira vivendo com menos de US\$1,90 por dia, considerada a atual linha internacional de extrema pobreza em purchasing power parity.

Percebe-se na crise da saúde provocada pela COVID-19 no Brasil, um enfrentamento diário pela "sobrevivência" e a própria manutenção da vida dos cidadãos brasileiros, os quais estão permanentemente cercados por discussões políticas e econômicas que "assolam" o país há décadas e trazem prejuízos irreparáveis à população. Guardada as devidas proporções, o meio ambiente no Brasil enfrenta desafios diários, os quais requerem também um esforço coletivo, mas principalmente do poder público em fazer cumprir a própria legislação do país. Atualmente, está em discussão, através de uma consulta pública, o Plano Nacional de Resíduos Sólidos (MMA, 2020), que representa a estratégia de longo prazo em âmbito nacional para operacionalizar as disposições legais, princípios, objetivos e diretrizes da Política Nacional de Resíduos Sólidos, instituída pela Lei no 12.305/2010 (Brasil, 2010), a qual foi sancionada a mais de dez anos, ou seja, há um verdadeiro retardamento na efetividade e cumprimento da lei.

No Brasil, assim como no caso da COVID-19, vive-se um retardamento político e uma ausência de efetiva gestão em nível federal (Ferigato et al., 2020) para a tomada de ações e medidas que possam reduzir a propagação do vírus, através da compra antecipada de vacinas, a imposição de restrições no trânsito e fluxo de pessoas, a abertura de mais hospitais e disponibilização de mais leitos para tratamento da COVID-19, dentre outros aspectos. 0 atual cenário pandêmico gera consequências graves ao país no âmbito da saúde, porém é necessário perceber os efeitos colaterais ao meio ambiente, pois o tratamento dos resíduos é transversal a diversas questões ambientais, sociais e econômicas e sua contribuição para mitigação do Sars-CoV-2 é considerável e não pode ser desprezada. 0 cuidado com o meio ambiente no Brasil deve ser uma pauta permanente nas diferentes esferas governamentais e também do coletivo populacional, pois o esforço na busca de solução para conter a COVID-19, deve servir de aprendizado e inspiração para manutenção adequada do tratamento dos resíduos sólidos no país. Não se pode negligenciar os efeitos da falta de cuidado e manutenção adequada ao meio ambiente, pois tudo o que é produzido e consumido tem sua origem na natureza.

\section{Conflito de interesses}

O autor declara não haver conflito de interesses.

\section{Referências}

ABRELPE - Associação Brasileira de Empresas de Limpeza Pública e Resíduos Especiais. Panorama dos Resíduos Sólidos no Brasil. Rio de Janeiro: ABRELPE, 2020. Disponível em: <https://abrelpe.org.br/panorama/>. Acesso em: 14 maio 2021.

ANCAT - Associação Nacional dos Catadores e Catadoras de Materiais Recicláveis. Anuário da reciclagem. São Paulo: ANCAT, 2020. Disponível em: <http://anuariodareciclagem. eco.br>. Acesso em: 18 maio 2021.

Bocchini, B. Destinação inadequada de lixo cresce 16\% em uma década. Agência Brasil, 2020. Disponível em: <https://agenciabrasil.ebc.com.br/saude/noticia/2020-12/ destinacao-inadequada-de-lixo-cresce-16-em-uma-decada>. Acesso em: 14 maio 2021. 
Brasil. Lei no 12.305, de 2 de agosto de 2010. Institui a Política Nacional de Resíduos Sólidos; altera a Lei no 9.605, de 12 de fevereiro de 1998; e dá outras providências. Disponível em: <http://www.planalto.gov.br/ccivil_03/_ato2007-2010/2010/lei/l12305. htm>. Acesso em: 23 maio 2021.

Ferigato, S.; Fernandez, M.; Amorim, M.; Ambrogi, I.; Fernandes, L. M. M.; Pacheco, R. The Brazilian government's mistakes in responding to the COVID-19 pandemic. The Lancet, v. 396, n. 10263, p. 1, 2020. https://doi.org/10.1016/S0140-6736(20)32164-4

Guimarães, S. Um dos efeitos colaterais da pandemia: o aumento da geração de lixo doméstico e hospitalar. Observatório de Justiça e Conservação. 2020. Disponível em: $<$ https://conexaoplaneta.com.br/blog/um-dos-efeitos-colaterais-da-pandemia-oaumento-da-geracao-de-lixo-domestico-e-hospitalar/>. Acesso em: 18 maio 2021.

IBGE - Instituto Brasileiro de Geografia e Estatística. Síntese de indicadores sociais: uma análise das condições de vida da população brasileira 2020. Rio de Janeiro: IBGE, 2020. (Estudos e Pesquisas. Informação Demográfica e Socioeconômica, n. 43). Disponível em: <https://biblioteca.ibge.gov.br/visualizacao/livros/liv101760.pdf>. Acesso em: 24 maio 2021.

JHU - Johns Hopkins University. COVID-19 dashboard by the Center for Systems Science and Engineering (CSSE). 2021. Disponível em: <https://coronavirus.jhu.edu/map.html>. Acesso em: 01 jul. 2021.

MMA - Ministério do Meio Ambiente. Plano Nacional de Resíduos Sólidos. Brasília: MMA, 2020. Disponível em: <http://consultaspublicas.mma.gov.br/planares/wpcontent/uploads/2020/07/Plano-Nacional-de-Resíduos-Sólidos-Consulta-Pública.pdf>. Acesso em: 18 maio 2021.

Taylor, L. COVID-19: Brazil's hospitals close to collapse as cases reach record high. BMJ, v. 372, n. 800, p. 1, 2021. https://doi.org/10.1136/bmj.n800

The Lancet. COVID-19 in Brazil: "So what?". The Lancet, v. 395, n. 10235, p. 1461, 2020. https://doi.org/10.1016/S0140-6736(20)31095-3

Informação da Licença: Este é um artigo Open Access distribuído sob os termos da Licença Creative Commons Attribution, que permite uso irrestrito, distribuição e reprodução em qualquer meio, desde que a obra original seja devidamente citada. 